\title{
Teaching Practices and Views of Evolution Instructors at Post-Secondary Institutions
}

\author{
Nicholas Wilbur* and Michelle Withers
}

\begin{abstract}
Background: The United States is ranked very low in acceptance of evolution among the public as compared to other countries, even though based on content standards, students should be exposed to evolutionary theory by the time they graduate from secondary school. Many studies have focused on how evolutionary theory is taught at the secondary level and the perspectives of the teachers. However, much less is known about these same issues in higher education. This study used a survey to collect responses from post-secondary instructors in the United States about how evolution is taught and how the individuals teaching the evolution courses perceive the theory and its role in shaping life on earth.

Results: Unlike secondary schools, there was much more consistency between the evolution curricula and attitudes of the instructors toward evolutionary theory at these post-secondary institutions. All types of institutions offer evolution-based courses or courses with evolution as a major topic of discussion at the introductory level, and most 4-year institutions also offer upper level evolution courses. Courses of all institution types address the same core elements of evolution. The vast majority of instructors accept the theory of evolution by natural selection as a biological explanation of the diversity of life on earth, although a small number still hold sympathetic views towards the teaching of Creationism and Intelligent Design.

Conclusions: Despite having such consistency among post-secondary instructors, college graduates as well as the public, remain diverse in their acceptance and understanding of evolutionary principles. Engaging student misconceptions and providing evidence for evolution can have an impact on many students, but there is still a sizable portion of the population that remains resistant. With the limited success that current evolution pedagogy is having on post-secondary students, it is important to focus research on improving teaching and advocacy in order to increase the impact that college instruction has on students' acceptance of evolution.
\end{abstract}

Keywords: Science education, Evolution education, Teaching, Biological evolution, Creationism, Post-secondary

\section{Background}

Evolution by natural selection is the unifying theory for biology that explains the amazing variety and fundamental connectedness of life on earth, yet acceptance of evolutionary theory among the public in the United States is very low. A 2006 study found that the U.S. ranked 33rd out of 34 countries surveyed in acceptance of evolution (Miller et al. 2006). A low rate of acceptance of evolution

*Correspondence: nwilbur@mix.wvu.edu

53 Campus Drive, 3142 Life Sciences Building, Po Box 6057, Morgantown, WV 26506-6057, USA is not unique to the United States. Studies have demonstrated that factors such as, high religiosity, low schoollife expectancy, low science literacy, and/or low GDP correlate to a lower acceptance of evolution among the public in other countries (Heddy and Nadelson 2012). However, when compared with countries that are similar with regard to these factors, the US tends to have lower levels of acceptance (Miller et al. 2006).

Religious beliefs may negatively influence learning about and acceptance of evolution (Köse 2010) leading to misconceptions and ignorance of basic evolutionary 
principles. This ignorance may further increase resistance to acceptance thus creating a self-reinforcing cycle. According to a 2014 Gallup poll, about $42 \%$ of Americans accept a Creationist view of human origins, defined as those claiming that "God created humans in their present form", and only about 19\% accept an explanation of evolution that does not involve divine influence. Nearly twice as many college students accept a creationist explanation of human origins as compared to college graduates (Gallup Incorporated 2014). However, previous Gallup polls (2006, $2008,2010,2012)$ show that college graduates are not consistently different from those with some college. The cause for this difference is unknown, but it does raise the question about what students are encountering in terms of evolution education as they progress through college.

A 2009 study by Moore and Cotner focusing on biology majors, found that the levels of acceptance by first year majors were not different from non-majors (Moore and Cotner 2009). Biology majors can encounter instruction on evolution throughout their entire degree program while non-science majors are more likely to encounter it only in introductory biology classes that may be used to fulfill general education science requirements. Rice et al. (2010) found that senior biology majors were more likely to accept evolutionary theory than introductory biology students. Whether this is due to selective retention of students with higher acceptance or an effect of their studies is unknown. However, even with the increase in acceptance only $57 \%$ of senior biology majors accept evolution.

There are many misconceptions about evolutionary theory held by college biology students (Alters and Nelson 2002). These incorrect misconceptions may contribute to resistance to learning basic evolutionary and biological principles leaving a considerable portion of the public, who are voters and policy makers, ignorant about the role of natural selection in important public health and ecological issues for our society (Gregory 2009). The lack of public support for evolution interferes with implementation and effectiveness of educational practices (Brem et al. 2003), increasing the risk of leaving a considerable portion of the public, including voters and policy makers, ignorant about the role of natural selection in important public health and ecological issues for our society (Gregory 2009; Nelson 2008). A public that does not have a working understanding of the world in which they live is at risk of making uninformed decisions that have negative impacts on all.

In order to better understand how to improve undergraduate evolution education, we must first have a clearer vision of the landscape of educational practices in evolution at the post-secondary level. While several studies have investigated evolution education in secondary education, examining teaching methods in addition to the acceptance by instructors, none have examined post-secondary evolution instruction on a national level. In 2002, Rutledge and Mitchell found that approximately one-third of secondary education biology teachers were unsure about or did not accept evolution and almost two-thirds devoted seven-days or less to the teaching of evolution (Rutledge and Mitchell 2002). This study also found that $69 \%$ of high-school teachers had never had a course in evolution, and 67\% had never had a course in the nature of science. Since college biology instructors commonly have degrees in biology or related sub-disciplines, we hypothesize that acceptance of evolution by instructors of the subject is more uniform at the college level and evolution instruction is more consistent across institutions. In order to test this hypothesis, we surveyed instructors of evolution at a variety of post-secondary institutions around the country on their teaching practices and personal views concerning evolutionary theory.

\section{Methods}

\section{Survey Design and Instrument}

We designed a survey to address teaching practices and acceptance of evolutionary theory at post-secondary institutions in the United States (see Additional file 1). The survey consisted of 30 questions-one adapted from a previous survey (Rice et al. 2010)-in four topic areas (see below) and was targeted at instructors of college courses where evolution was either the only or a primary topic. Before distribution, questions were reviewed by two evolution education researchers, a national advocate of evolution education and a survey design specialist. Participation in any question was voluntary and responses from all participants who indicated that they teach a class where evolution is at least a major topic, were used for analysis. Responses from participants only completing demographics portion of the survey, or less, were not used in reported analyses $(n=42)$. A small number of participants skipped particular sections of questions: 15/523 did not respond to questions concerning information about the course(s) they teach (15 participants), and 16/523 did not respond to questions concerning personal views on teaching and evolution (16 participants). Responses that those participants provided in other sections were included in analyses. Respondents who taught more than one course were given the opportunity to answer the course information questions for each course. For responses on course-based items, e.g., the level at which a course is taught-freshmen, sophomore, junior, senior-all courses were included in data analysis. However, for questions that pertained to instructor-based practices, e.g. instructional strategy-active learning, lecture or both-only answers about primary courses were used in the analysis to avoid over representation of the teaching practices of any single 
instructor. Any respondents who accessed the survey and indicated that they did not teach a course with evolution as at least a major topic were directed to an exit page.

The survey collected responses in four topic areas regarding the teaching and acceptance of evolutionary theory by instructors at post-secondary institutions:

1. Institutional demographics: six questions on institution type (using simplified Carnegie Classification designations, Carnegie Foundation for the Advancement of Teaching 2010), religious affiliation and department size.

2. Course information: ten questions on class enrollment, frequency of offerings, course level (freshmangraduate), and course topics.

3. Instructional methods and materials: four questions on primary method[s] of instruction and required resources.

4. Instructor views: nine questions on perceptions of what should be taught in an evolution course and personal acceptance of the theory of evolutionary.

\section{Distribution and Participant Selection}

The survey was administered using Survey Monkey. One thousand eighty-four post-secondary institutions were randomly selected from the Carnegie Classification of Institutes of Higher Education website which compiles information on the accredited post-secondary institutions in the United States. The proportion of each institutional type, Tribal, Associates, Bachelors, Masters, and Research Universities, to which surveys were sent, reflected their national representation. As defined by the Carnegie Foundation:

- Tribal schools are those that belong to American Indian Higher Education Consortium;

- Associate Institutions are those in which the highest awarded degree is an associate degree or bachelor degrees constitute less than 10\% of awarded degrees per year;

- Bachelor Institutions award more than 10\% of their degrees as bachelors and less than 50 masters degrees per year;

- Masters Institutions are those that award at least 50 master degrees and less than 20 doctoral degrees per year; and

- Research Universities (or Doctorate Granting) are those that award at least 20 doctoral degrees per year.

Surveys were distributed through direct email to instructors of evolution as determined by institutional faculty listings on department websites, if known, and to department heads if not. The cover letter sent to participants and first section on the survey specified inclusion requirements and those that did not meet the requirements were directed to an exit page. Technical and specialty schools were not included due to a common lack of biology courses taught by these institutional types.

\section{Statistical Analysis and Response Reliability}

Raw data were collected from Survey Monkey and reported as percentages. Chi square $\left(X^{2}\right)$ tests were performed to compare responses from each institution type. All statistical analyses were performed using JMP (SAS) software.

Post-hoc Long-String index (Meade and Craig 2011) was calculated on responses to identify "careless responses." The longest string of consecutive responses was 20 (out of 72 items). All strings that were longer than five occurred in the section where participants indicated which topics were included in their courses. Having long strings of consecutive similar responses in this section would be entirely appropriate for people teaching classes where they covered some or all of the provided topics at a similar level. In addition to calculating long strings, we analyzed responses to consecutive questions that required reverse responses in order to be logically consistent. For example, if a respondent strongly agreed that "Only evolution should be taught as valid science," they should not also strongly agree that "Only Intelligent Design/Creationism should be taught as valid science". There were no instances of participants providing mutually exclusive responses to these sets of consecutive questions.

\section{Results}

\section{Response Rates}

While much is known about the state of evolution instruction at the secondary level, relatively few studies have investigated how evolution is being taught at the post-secondary level. To reveal the national landscape of teaching practices and views of evolutionary theory at the post-secondary level, an electronic survey was distributed to instructors of evolution at institutions throughout the United States. Institutions $(n=1,084)$ were randomly selected from the Carnegie Foundation Basic Classification of Accredited Institutions of Higher Education list. Our sample constituted 30\% of the total institutions listed on the website. The ratio of institutional types selected reflected their national representation. The overall response rate of institutions contacted by direct-email was 30\% $(324 / 1,084)$ with the highest response rate occurring for Research Universities $(86 \%, 73 / 85)$, followed by tribal colleges $(44 \%$, 4/9), 4-year Bachelors and Masters granting institutions 
$(28 \%, 123 / 440)$ and Associate schools (16\%, 88/550). In order to increase the number of respondents, the survey was also distributed through listservs for several professional societies and organizations related to biology research or education research. Results from the random and non-random distribution methods were analyzed separately and found not to be significantly different $\left(X^{2}, \mathrm{p}>0.05\right)$, therefore data were pooled for all respondents $(n=523)$. Response rates for pooled data could not be calculated, however representation of each institutional type was found to be $41 \%$ for Research Universities $(n=216), 32 \%$ for Bachelor and Master Institutions $(\mathrm{n}=164), 25 \%$ for 2 -year Associates colleges $(n=131)$, and $2 \%$ Tribal/Other colleges $(n=12)$. Institutions with religious affiliation were found in each institutional type, except Associate schools, and represent $20 \%$ of the total $(n=107)$.

Non-Content Aspects of Post-Secondary Evolution Courses At all institutional types, more than half of the courses where evolution is a [the] primary topic, are taught at the freshmen (35\%) and sophomore (29\%) levels (All Courses; Fig. 1). However, the specific distributions of evolution courses across different class levels are significantly different between institutional types $\left[X^{2}(12\right.$, $N=781)=128.5, \mathrm{p}<0.01]$, with the biggest difference at Associate schools. Given their 2-year nature, freshman and sophomore courses represent the vast majority of their evolution courses. The four-year Bachelors and Masters institutions have a slightly more equal distribution of evolution courses across the undergraduate levels while Research institutions and Tribal colleges follow the trend of the whole group which is skewed more toward the first two years with junior
(18\%), senior (15\%) and graduate (3\%) level courses making up the remainder. This same trend holds for courses addressing evolution when it is not a primary component. Interestingly, when institutions with a religious affiliation are grouped together, they demonstrated a trend toward slightly more upper level evolution courses.

The majority of respondents, regardless of school type, reported using a mixture of lecture and active learning (66\%), while nearly a quarter use lecture alone (22\%) and only a small percentage use active learning alone $(8 \%)$ in their primary survey courses, defined as the course where evolution is the most heavily emphasized (Fig. 2). When separated by institution type, there were significant differences in the extent to which instructors relied on the different teaching methods $\left[X^{2}(12, N=781)=128.5, \mathrm{p}<0.01\right]$. While the majority still relied on mixed methods, instructors at 2-and 4-year institutions tended to use lecture alone much more often than active learning alone, while those from research and tribal institutions tended to balance the amount of lecture only and active learning only courses. In terms of the instructional materials used, the textbook is the tool of choice for $91 \%$ of primary survey courses. The use of online resources (64\%) and primary literature $(53 \%)$ are also fairly common, with secondary literature being used in a little over a third (36\%) of courses (Fig. 3). The differences in resource use between institutional types were not significant $\left[X^{2}(12\right.$, $N=445)=19.53$, p > 0.05], however, 2-year institutions tend toward the lowest use of primary literature, while tribal colleges lead the pack. Surprisingly, research institutions fall in the lower to middle range for use of primary literature.

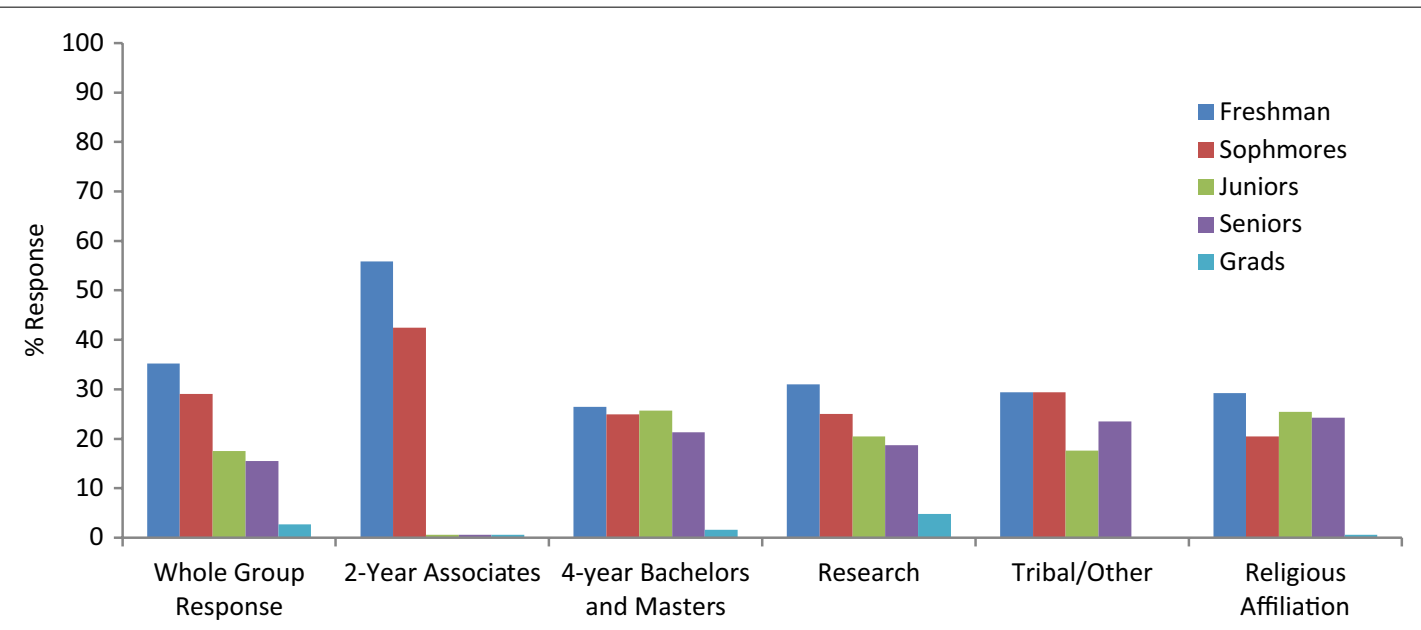

Fig. 1 Distribution of evolution courses at different class levels. The frequency distribution for evolution courses at different class levels was significantly different between institutional types $\left[X^{2}(12, N=781)=128.5, p<0.01\right]$. 


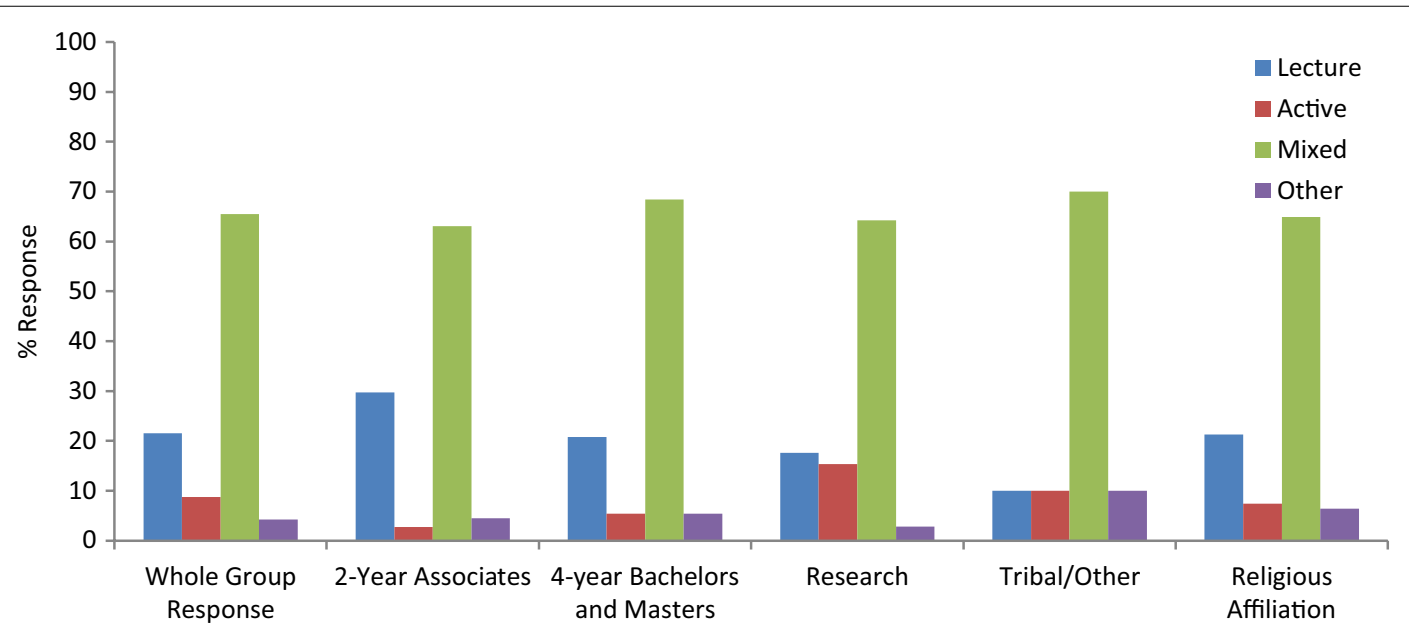

Fig. 2 Distribution of primary instructional methods used. The frequency distribution for different methods of instruction was significantly different between institution types $\left[X^{2}(12, N=446)=23.15, p=0.006\right]$.

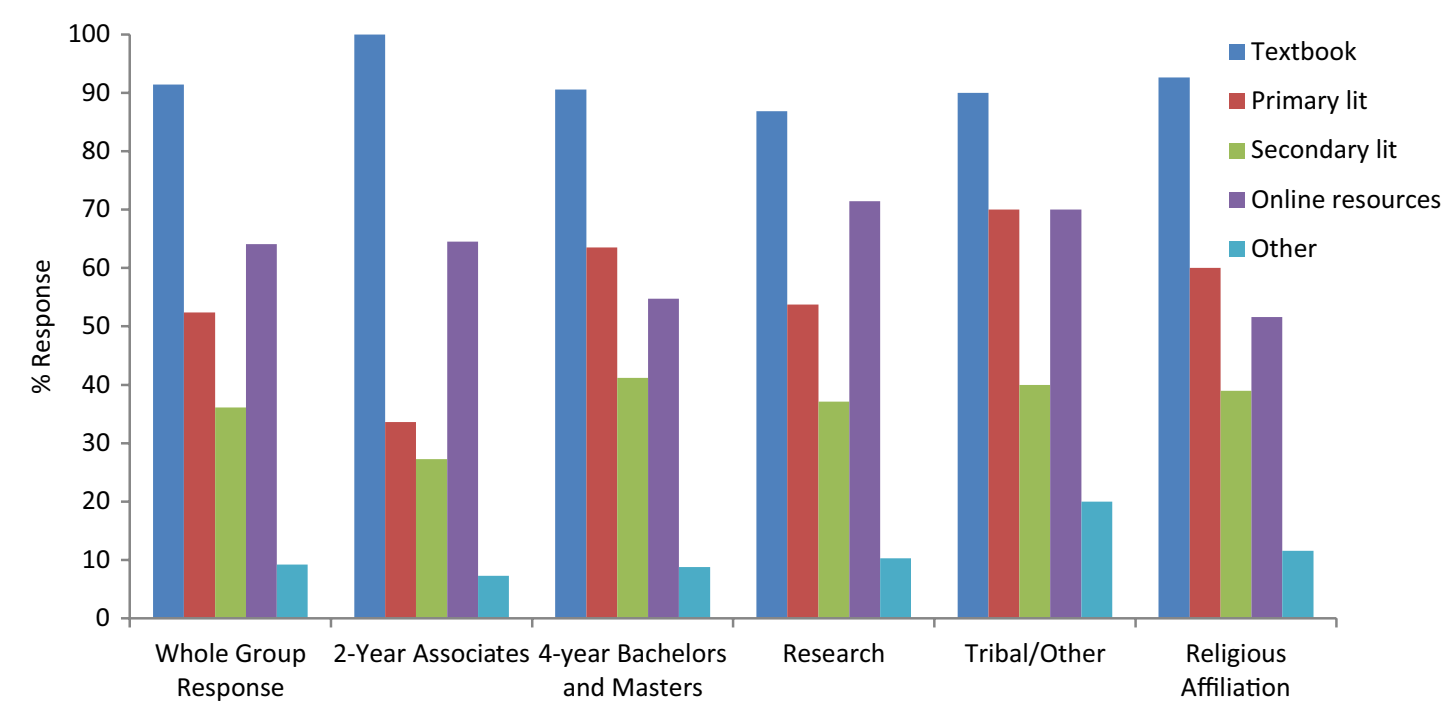

Fig. 3 Distribution of instructional resources used. The frequency distribution of instructional resources was not significantly different between institution types $\left[X^{2}(12, N=445)=19.53, p>0.05\right]$.

\section{Course Content in Post-Secondary Evolution Education}

In courses where evolution is at least a primary component, if not the sole topic, respondents report covering a wide range of aspects of evolutionary theory [3-way Chi Square used to compare all courses; Not Addressed $X^{2}(57, N=438)=49.1$; Addressed Superficially $X^{2}(57, N=438)=40.52$; Addressed Significantly $X^{2}(57, N=438)=21.66$, p > 0.05; Fig. 4]. Of the twenty sub-topics of evolution that we queried, at least $40 \%$ of respondents reported giving all topics significant coverage in their course and at least $75 \%$ gave significant coverage to six of the sub-topics. These six most commonly taught topics include Mechanisms of Natural Selection, Mutations and Sources of Variation, Adaptation, Lines of Evidence for Evolution, Genetics, and Speciation. The three least commonly taught subtopics were The life of Charles Darwin, Rates of Evolution, and History of Life on Earth.

When asked whether their institutions had official regulations about the teaching of alternatives to evolutionary theory, the vast majority of respondents (84\%) report having no institutional directive concerning the inclusion or exclusion of Creationism or Intelligent Design in their evolution courses; however a small fraction $(2 \%)$ of 


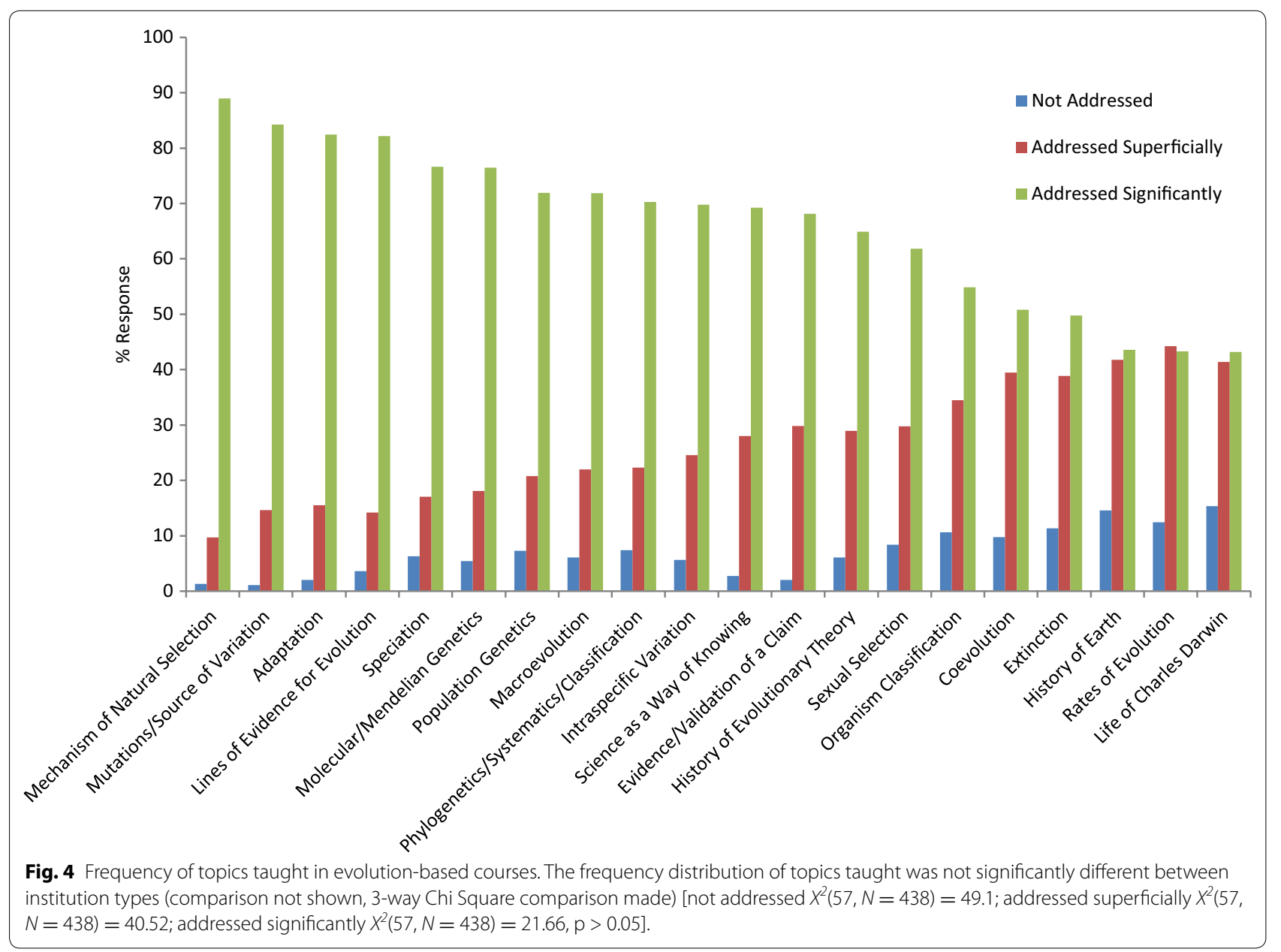

instructors reported having an institutional ban to teaching alternatives to evolution (Fig. 5). Those answering that they didn't know if their institution had requirements (14\%) were removed from data analysis and there were no significant differences between institution types $\left[X^{2}(9, N=441)=9.87, \mathrm{p}>0.05\right]$. While 106 respondents were from institutions with religious affiliations, only a single respondent reported that their institution required the teaching of alternatives to evolutionary theory.

\section{Instructor Perspectives on Evolutionary Theory}

Unlike secondary education, evolution instructors at post-secondary institutions nearly always have postgraduate degrees, with the vast majority of those being doctoral degrees (81\%) (Fig. 6). Associate schools have slightly more instructors with Masters' degrees than doctoral degrees while instructors from the remaining institutional types nearly always have doctoral degrees $\left[X^{2}(12, N=479)=199, \mathrm{p}<0.01\right]$. Not surprising given the similarity in their level of training, post-secondary evolution instructors are also much more consistent in their personal views of evolutionary theory as compared to secondary teachers. In order to understand how their views aligned with the topics they were teaching, we asked whether or not alternatives to evolution should be or were included in instruction. Nearly $99 \%$ of respondents agreed that biological evolution should be taught in college science classes. Just over half of the respondents (53\%) felt that only biological evolution should be taught in college science classes, while slightly fewer (44\%) felt that addressing why intelligent design/creationism are not scientific could be used to teach nature of science. A very small fraction, 3 respondents from research institutions and 5 from 4-year institutions (1.8\%), felt that both evolution and alternative ideas should be taught as valid science. An equally small proportion, 3 respondents from research institutions and 3 from associate institutions (1.6\%), felt that neither should be taught as valid science. Only a single respondent reported that only Intelligent Design/Creationism should be taught as valid science (Fig. 7a). When separated by institutional type, there were no significant differences in the views of instructors 

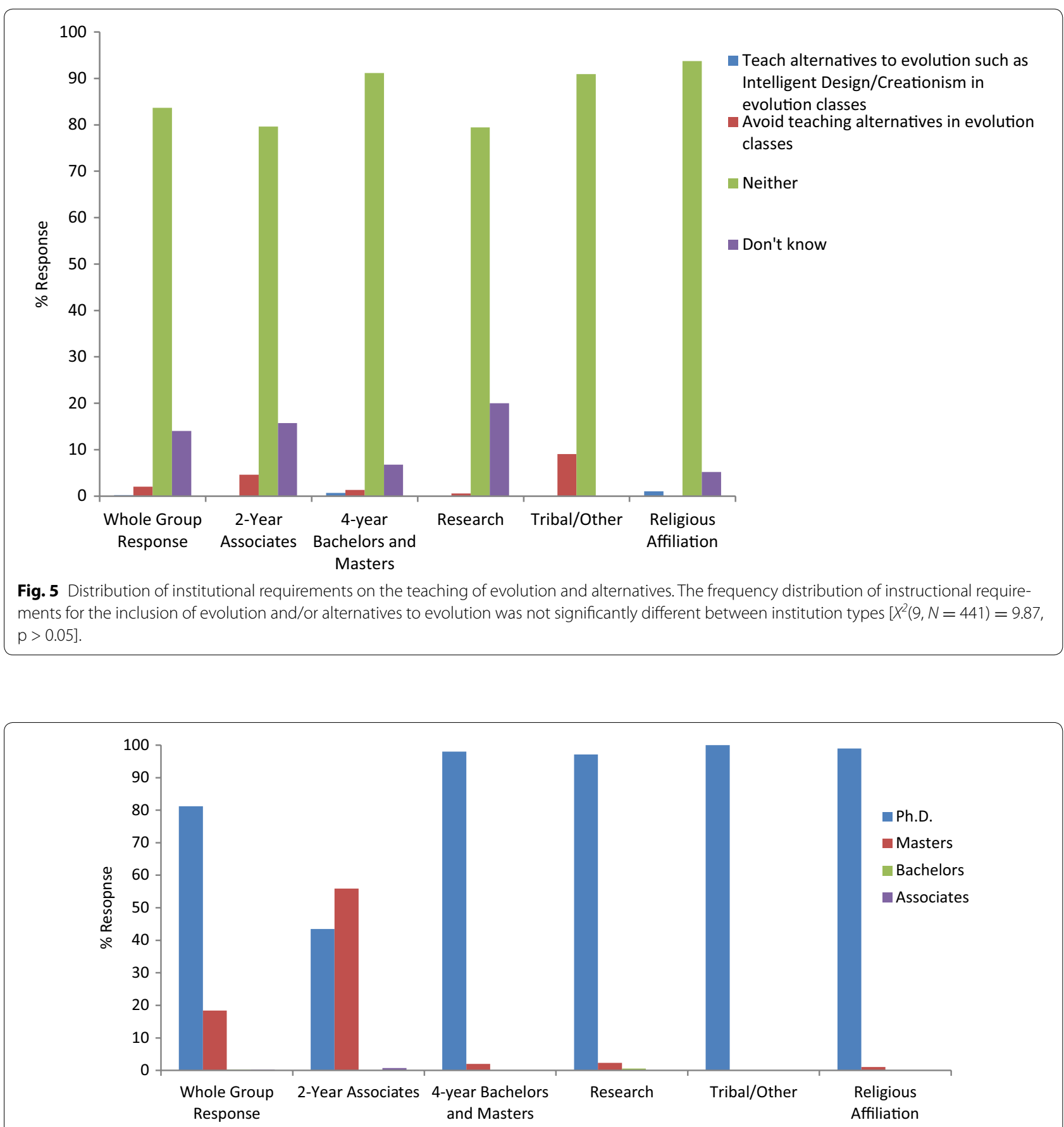

Fig. 6 Highest degree earned by instructors. The frequency distribution of highest degree earned by instructors was significantly different between institution types $\left[X^{2}(12, N=479)=199, p<0.01\right]$.

$\left(X^{2}(12, N=173)=11.7, \mathrm{p}>0.05\right)$. There was no significant difference between how instructors felt evolution should be taught and how they actually taught it $\left[X^{2}(12\right.$, $\mathrm{N}=172)=9.5, \mathrm{p}>0.05$; Fig. 7b], but many attributed discrepancies that were present to a lack of available time to discuss unscientific alternatives.
In addition to querying instructors about their perspectives on what should be taught in their evolution courses, we also wanted to determine how their personal beliefs meshed with what the theory of evolution tells us about the origin and evolution of life on our planet. In order to gather this information in a quantifiable way, we created 


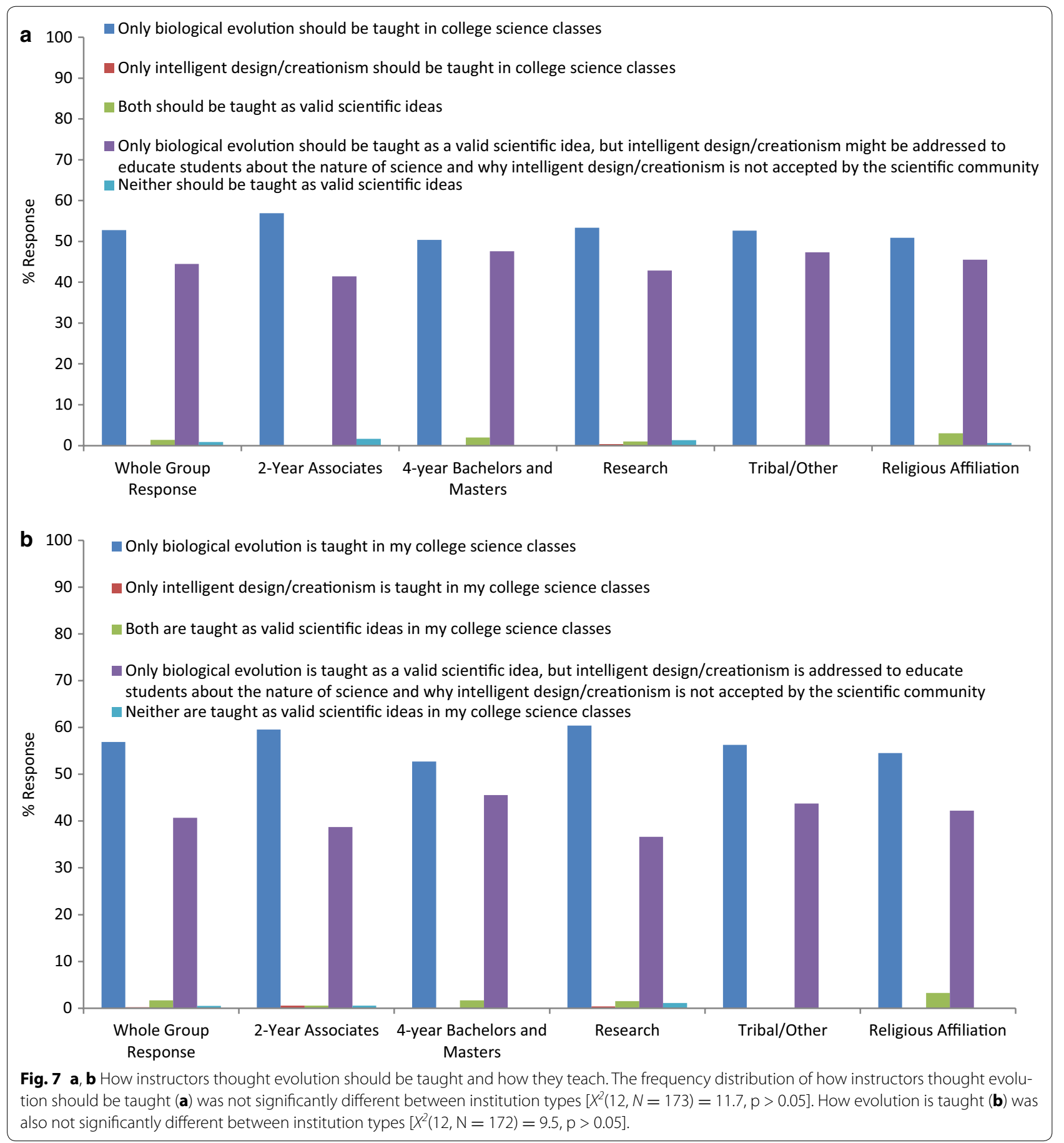

a question with several different descriptions of the age of the earth and explanations for the diversity of life from which respondents were asked to select the option that most fit their own beliefs. It was critical, since the options were provided for the respondents rather than allowing for an open-ended response, to have as comprehensive a set of choices as possible. So we looked to other related surveys for models of questions (Rice et al. 2010) and sought input from a senior advisor at the National Academy of Sciences who was involved in the publication of the report, Science, Evolution and Creationism (National Academy of Sciences and Institute of Medicine 2008). The choices allowed respondents to self-identify as young earth creationists, old earth creationists, old 
earth evolutionists who believe that evolution occurs with divine intervention, old earth evolutionists who believe that evolution supports the existence of a deity, old earth evolutionists who believe that evolution neither supports nor denies the existence of a deity, or old earth evolutionists who believe that evolution denies the existence of a deity (Fig. 8). The responses were not significantly different from different institutional types $\left[X^{2}(15, N=443)=12.42, \mathrm{p}>0.05\right]$. The vast majority of respondents (93\%) identified as old earth evolutionists. A large proportion of those ( $83 \%$ of the total) perceive evolution as a natural process that neither supports nor refutes the existence of a God, and nearly equal proportions who believe that evolution refutes $(6 \%)$ or supports (4\%) the existence of a god. Only two respondents believe that evolution occurs with God's intervention and only a single respondent identified as a young earth creationist. Two of those three were from institutions with religious affiliations. Respondents were given the option to select a seventh choice if they felt that none of the options represented their views (light blue bars). These respondents $(6 \%)$ were asked to supply a description of their perspective. Below are a few representative responses:

- I agree with the last option but I don't agree that biological evolution supports the idea that God does not exist. Rather, scientific evidence supports that God does not exist, i.e. that supernatural phenomenon do not occur.

- Biological evolution happened on a planet that is now billions of years old and has nothing to do with a God.

- Statement 3 (ancient earth, but God has intervened) and statement 5 (ancient earth, and evolution neither supports nor denies God) I believe are equally close to my perspective and I couldn't pick between them.

The final question on instructor perspectives queried respondents' perspectives on the role of evolution in the origin of life, the origin of humans and the diversity

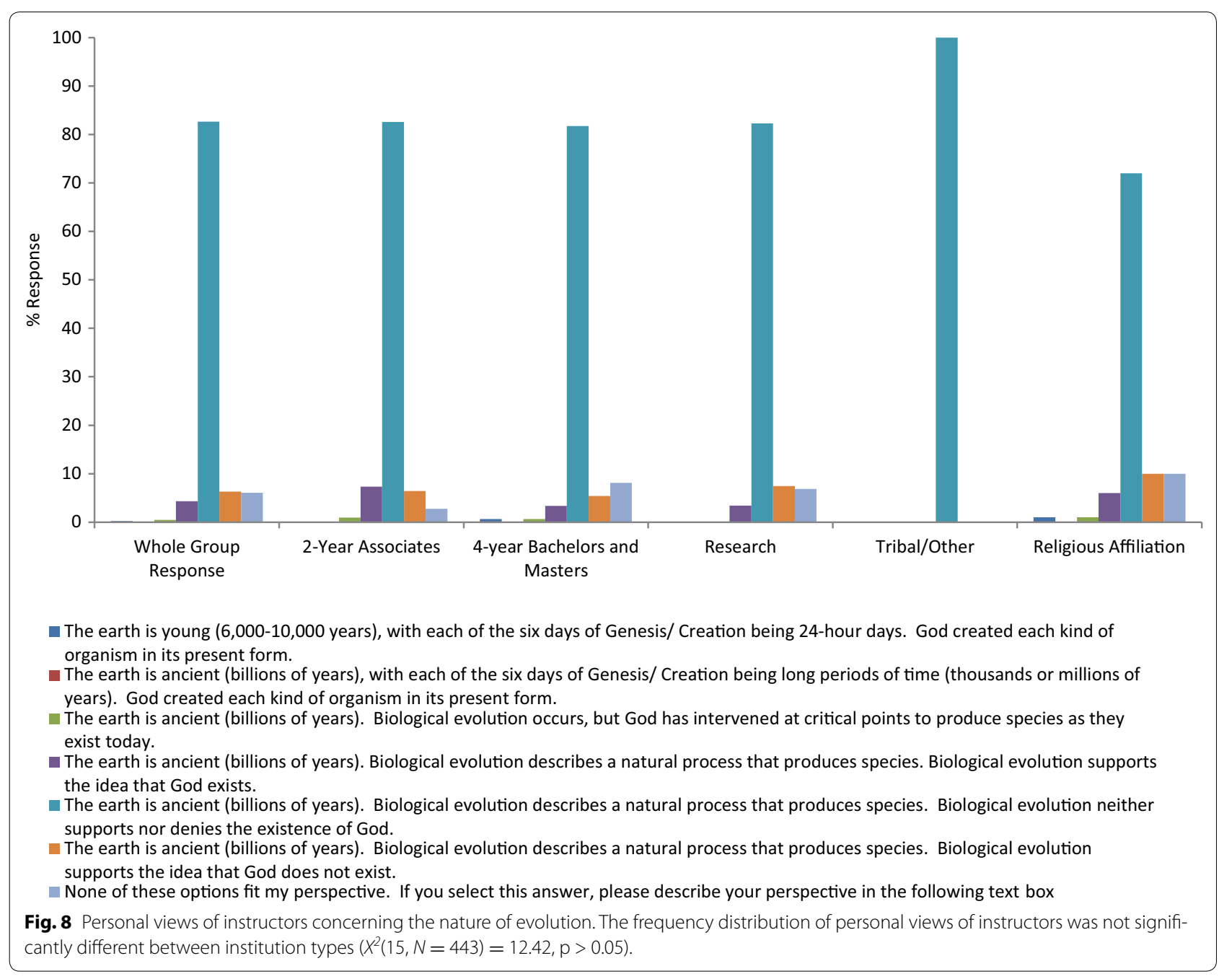


of life forms on earth. Most participants agreed or strongly agreed that the theory of evolution explained the diversity of species (98\%), and the origin of humans (94\%). Surprisingly, a large proportion (66\%) also felt that it explained the origin of life on earth. Only $25 \%$ of respondents disagreed with this statement. A small proportion of respondents (2\%) disagreed with all three statements. Responses were not significantly different between institutional types (3-way Chi Square comparison made: Disagree $X^{2}(6, N=442)=4.0$; Neutral $X^{2}(6$, $N=442)=7.5$; Agree $\left.X^{2}(6, N=442)=1.5, \mathrm{p}>0.05\right)$. The greatest variation in responses arises from the idea that evolution explains the origin of life on earth (Fig. 9). Research and 2-year institutions had the lowest agreement with that idea while all but Tribal colleges have a slightly lower agreement with evolution explaining the evolution of humans as compared to the diversity of life.

\section{Discussion}

In order to understand the influences of student acceptance of evolution, we should first recognize the context in which American students are learning evolution. The purpose of this study has been to elucidate the landscape of teaching practices and instructor perspectives related to post-secondary evolution education. Despite major differences between the practices and perspectives of instructors who teach evolution in secondary education (Rutledge and Mitchell 2002), post-secondary evolution instruction is relatively consistent.

We achieved an acceptable overall response rate from our randomized sample (Holbrook et al. 2005). The specific response rates by institution were quite different ranging from an excellent response rate from Research Institutions to a low response rate from 2-year Associate schools. Therefore our strongest conclusions can be drawn for Research, Tribal and 4-year Bachelors and Masters Institutions. However, given the consistency in responses across all institutional types, the lower response rate from 2-year institutions may still constitute an accurate representation. The possible absence of a Biology Department or classes with at least an emphasis on evolution may have contributed to the lower response rate from 2-year institutions and thus may constitute an acceptable rate of responses from schools with those classes.

Since evolution is a fundamental organizing principle of biology, we were not surprised to find that, regardless of institutional type, half or more of the evolution courses were taught during the first two years of college. Upper

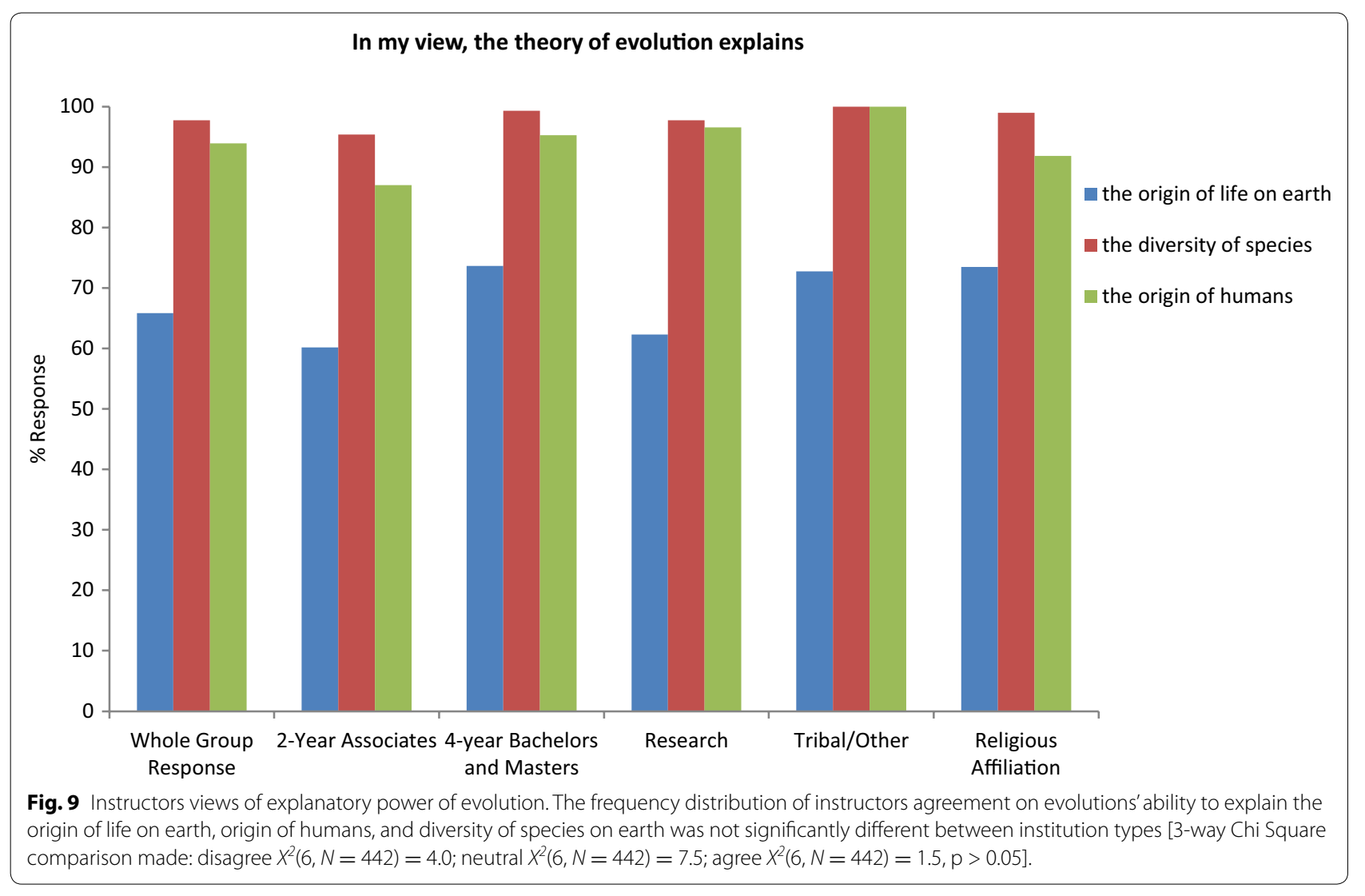


level courses are often taught by faculty with specializations in that topic area. Since departments can differ drastically in their faculty representation of different subdisciplines of biology, we were not surprised to see more variety in the proportion of upper level courses in evolution. At first glance, we did not expect to see such a high proportion of mixed lecture and active learning classes given the somewhat preliminary state of biology education reform at most post-secondary institutions. However, upon further reflection, the ambiguity of the label and the broad possible interpretations of the respondent, the mixed label could be applied to a range of courses from primarily lecture with a few open-ended questions to mostly interactive with occasional mini-lectures to set up or reflect upon learning activities. What our data do not demonstrate is the proportion of engagement in the mixed classes. By definition a lecture-only course would have negligible, if any, interaction with students and even though most post-secondary biology faculty probably have not had formal pedagogical training, we would still expect there to be at least some interaction with students in most courses. Given the less ambiguous nature of the active learning only label, we expect that respondents who chose this designation, in fact, were teaching reformed classes using active learning approaches. While we would like to see a much higher representation of that approach, we were pleased to see that, at Research and Tribal institutions, there were at least as many active only as lecture only courses. We expect that on average, class sizes at 2- and 4-year institutions are smaller than those at research institutions; therefore we were somewhat surprised to see that those institutions have a much higher proportion of lecture-only courses compared to active only. For 2-year institutions, this may arise from perceived constraints on content coverage imposed by the institutions into which their students feed.

Textbooks are ubiquitous on college campuses, especially for use in lower level courses, so it is not surprising that they were reported as the primary content resource, regardless of institution type. Given that we were querying science instructors, we were gratified to see that primary literature was employed by more than half of the respondents from most institutions. However, because primary literature is more commonly employed in upper level courses, those could account for much of what is reported here. This might also explain why 2-year associate schools reported less reliance on primary literature because nearly all of their courses are taught at the freshmen and sophomore levels. Pedagogical reform efforts in biology promote authentic research experiences and use of primary literature earlier in the undergraduate experience, so we would expect use of primary literature to increase as education reform spreads. Online resources, although the newest form of instructional tool queried, is second only to the textbook in frequency of use by the group as a whole. Accessibility and utility, especially in large enrollment courses, likely account for a large part of the popularity of this resource whose use will probably continue to rise as more and more resources and platforms become available in this format. There was relatively little variation among topics taught in evolution-based courses, with very few topics that were not at least addressed in most courses. The most commonly taught topics address the core mechanisms and evidence for evolution. Open-ended responses revealed that when facing time constraints, instructors prioritize addressing these core concepts over what they considered to be more "historical" or "contextual" topics. Research on the limited effectiveness of using evidence for evolution to convince some evolution skeptics might call into question this prioritization (Ingram and Nelson 2006; Rice et al. 2010; Verhey 2005).

The vast majority of instructors indicated that their institutions have no requirements for teaching either evolution or alternatives to evolution. Despite the lack of oversight, most evolution courses include only evolution as valid science, while the majority of those that include alternatives do so as examples of non-science. We attribute this consistency in the way evolution is taught to the uniform level of training for its instructors. Nearly all respondents indicated holding professional degrees with the majority being doctorates. Another factor that may contribute this consistent picture is a bias in who responded based on the voluntary nature of the survey. Instructors who teach creationism in evolution classes may be less likely to either take the survey or report teaching alternatives to evolution even on a survey where responses were anonymous. This bias might also extend to underrepresentation of the teaching of alternatives at institutions with religious affiliations. Based on our pool of respondents, only a single instructor indicated a requirement for teaching alternatives to evolution in their class. While this person was from a school with a religious affiliation, it was not representative of the norm, for our respondents. Differences between what respondents thought should be taught and what was taught were often attributed to time constraints, however a few participants indicated a fear that any time spent discussing alternatives may impart undue credence to those topics as valid science.

Uniform training and the selective nature of biological training, likely accounts for the consistency in evolution instructor beliefs and perspectives as well. While nearly $42 \%$ of Americans claim that "God created human beings pretty much in their present form at one time within the last 10,000 years or so (Gallup Incorporated 2014)", 
only a single respondent reported holding creationist views. As stated earlier, selection bias might be causing an underrepresentation of this group because evolution instructors who hold creationist views might be less likely to participate in the survey. Comparing answers to other questions in that same Gallup poll, our instructors are very different in their beliefs compared to the general public. Less than $1 \%$ of our respondents believe that evolution occurs with intervention from a deity compare to $39 \%$ of Americans claimed that "Human beings have developed over millions of years from less advanced forms of life, but God guided this process". The stark contrast between the views of evolution by college evolution educators and the American public highlights the desperate need for better communication between scientists and the public, more effective education strategies and more effective advocacy efforts.

The final question in the survey probed instructors' perspectives on the role of evolution in three different phenomena: origin of life, diversity of life, and origin of humans. Seeing agreement from nearly all respondents that evolution explains the diversity of life is in accord with the fact that the vast majority of respondents selfidentified as old earth evolutionists who saw no connection between evolutionary theory and the presence or absence of a god. However, for all but Tribal colleges, a slightly smaller percentage of respondents agreed that evolution explained human origins. The discrepancy in the two responses is interesting in that it mirrors, on a much smaller scale, the difference in acceptance by the general public of microevolution versus macroevolution. A subset of the general public has no problem accepting the idea that allele frequencies change from one generation to the next, but still adamantly refuse to accept that evolution can account for the origin of humans. Of the three responses, the fact that nearly two-thirds of our respondents agreed that evolution also accounted for the origin of life was perhaps the most puzzling. While the level of agreement was much lower than for the previous two phenomena, we were surprised that there was any agreement given that the origin of life is still an unanswered question and that biological evolution acts on living organisms. We have two possible explanations for these responses. The first, we did not specify "biological" evolution in the question, so it is possible that some respondents extended the definition of evolution to encompass chemical evolution. The second possibility is that there is a misunderstanding by a subset of evolution instructors that biological evolution does account of the origin of life. Instructors who teach introductory courses spend the majority of their time teaching subjects outside of their sub-disciplinary specialty due to the sheer breadth of topics covered in those courses. Coupled with the fact that "history of life on earth" is one of the least commonly taught topics, it is easy to imagine that instructors who know and accept evolutionary theory would have no problem extending that acceptance to an aspect of evolution with which they are not familiar.

\section{Conclusions}

Public acceptance of evolution in the United States is at an unsettling level. Although acceptance of evolution tends to be higher among college graduates, it is still low among those with less education. Secondary education biology teachers are varied in their acceptance of evolution and the degree to which they implement evolution in their classes (Rutledge and Mitchell 2002). However, this is not the case among post-secondary instructors where evolution is a common and widespread topic. Most postsecondary instructors share similar views of evolution as well as what topics should be included in evolution-based courses. Despite this, there are an alarming number of students enrolled in and graduating from biology programs with sympathetic views towards Creationism and Intelligent Design (Brem et al. 2003; Ingram and Nelson 2006). Engaging student misconceptions and providing evidence for evolution can have an impact on many students, but there is still a sizable portion of the population that remains resistant. With the limited success that current evolution pedagogy is having on post-secondary students (Silva 2012), it is important to focus research on improving teaching and advocacy in order to increase the impact that college instruction has on students' acceptance of evolution.

\section{Additional File}

Additional file 1: Evolution evaluation.

\section{Authors' Contributions}

NW and MW both contributed to the design of the survey as well as all procedural components of the study. NW performed the compilation of survey participants from the Carnegie Foundation and administered the distribution of the survey. NW also performed all data collection and statistical analyses. MW distributed the survey through list-servs and assisted with statistical analysis. Both NW and MW were involved in writing, editing and revising the completed manuscript. Both authors read and approved the final manuscript.

\section{Acknowledgements}

We thank Jay Labov and Justin Rice for their assistance and advice in the creation of the survey tool. We thank Sebastian Diaz for his assistance with survey development and reliability analysis. We would also like to thank Jim Belanger for his support in providing revisions to the manuscript and Kristin Duling for her assistance with determining response reliability among survey participants.

\section{Compliance with Ethical Guidelines}

\section{Competing Interests}

The authors declares that they have no competing interest. 
Received: 15 April 2015 Accepted: 11 July 2015

Published online: 05 August 2015

\section{References}

Alters, B., \& Nelson, C. (2002). Perspectives: teaching evolution in higher education. International Journal of Organic Evolution, 56(10), 1891-1901.

Brem, S., Ranney, M., \& Schindle, J. (2003). Perceived consequences of evolution: college students perceive negative personal and social impact in evolutionary theory. Science Education, 87, 181-206.

Carnegie Foundation for the Advancement of Teaching. (2010). Basic classification tables. http://carnegieclassifications.iu.edu/descriptions/basic.php.

Gallup Incorporated. (2006, 2008, 2010, 2012, 2014). http://www.gallup.com/ home.aspx.

Gregory, T. (2009). Understanding natural selection: essential concepts and common misconceptions. Evolution Education and Outreach, 2, 156-175. doi:10.1007/s12052-009-0128-1.

Heddy, B., \& Nadelson, L. (2012). A global perspective of the variables associated with acceptance of evolution. Evolution Education and Outreach, 5(3). doi:10.1007/s12052-012-0423-0.

Holbrook, A., Krosnick, J., \& Pfent, A. (2005). The causes and consequences of response rates in surveys by the News Media and Government Contractor Survey Research Firms. In Advances in Telephone Survey Methodology (pp. 499-590). John Wiley \& Sons, Inc.

Ingram, E, \& Nelson, C. (2006). Relationship between achievement and students' acceptance of evolution or creation in an upper-level evolution course. Journal of Research in Science Teaching, 3(1), 7-24.

Köse, E. (2010). Biology students' and teachers'religious beliefs and attitudes towards theory of evolution. H.U. Journal of Education, 38, 189-200.
Meade, A., \& Craig, S. (2011). Identifying careless responses in survey data. Paper presented at the 26th Annual Meeting of the Society for Industrial and Organizational Psychology, Chicago.

Miller, J., Scott, E., \& Okamoto, S. (2006). Public acceptance of evolution. Science, 313, 765-766.

Moore, R, \& Cotner, S. (2009). The creationist down the hall: does it matter when teachers teach creationism? Bioscience. 59(5), 429-435.

National Academy of Sciences and Institute of Medicine. (2008). Science, Evolution, and Creationism. Washington, D.C.: The National Academies Press.

Nelson, C. (2008). Teaching evolution (and all of biology) more effectively: Strategies for engagement, critical reasoning, and confronting misconceptions. Integrative and Comparative Biology, 48(2), 213-212.

Rice, J., Olson, J., \& Colbert, J. (2010). University evolution education: the effect of evolution instruction on biology majors' content knowledge, attitude toward evolution, and theistic position. Evolution Education and Outreach. doi:10.1007/s12052-010-0289-y.

Rutledge, M., \& Mitchell, M. (2002). Secondary education biology teachers' knowledge structure, acceptance and teaching of evolution. The American Biology Teacher, 64(1), 21-28.

Silva, K. (2012). Evolution-centered teaching of biology. Annual Review of Genomics and Human Genetics, 13, 363-380. doi:10.1146/ annurev-genom-090711-163749.

Verhey, S. (2005). The effect of engaging prior learning on student attitudes toward creationism and evolution. Bioscience, 55(11), 996-1003.

\section{Submit your manuscript to a SpringerOpen ${ }^{\odot}$ journal and benefit from:}

- Convenient online submission

- Rigorous peer review

- Immediate publication on acceptance

- Open access: articles freely available online

- High visibility within the field

- Retaining the copyright to your article

Submit your next manuscript at $\boldsymbol{~ s p r i n g e r o p e n . c o m ~}$ 